\title{
Orality versus literacy in the Nigerian SMS discourse
}

\author{
Endong, Floribert Patrick C. \\ University of Calabar, Nigeria \\ Essoh, Ndobo Eugenie Grace \\ University of Calabar, Nigeria
}

\section{Introduction}

As an emergent form of technological communication, SMS texting has engendered a different type of language use and a new orthography which remarkably deviates from language norms (Essoh et al 2014; Odey et al 2014; Barasa and Mous 2013; Awoyemi 2013; Soffer 2012; Richardson and Lenarcic 2009; Feuba 2009; Bodomo 2006, Ling 2005). This emergent language use and postmodern orthography - which is variously labelled as webslang, internet slang, digital language, netlingua or textese - often combines qualities of both the oral and written language. Indeed, the textese linguistic form is generally considered as a fruit of linguistic creativity. It is an independent written register which, somehow borrows from the standard written language. Yet, it lies on such creative methods of sentence framing as multilingualism (tag switching), as well as on word/ sentence shortening techniques such as graphones, word/number homophones, abbreviation, single pronounceable letters, and the use of numerals among others.

The textese is therefore a kind of "hybrid" linguistic production. It often integrates conventional spelling of words (which according to this article would be considered literacy features) and creative/unconventional formulations such as abbreviations, graphones or word/number homophones (linguistic phenomena in which words are spelt the way they are pronounced). According to Soffer (2012:32) the hybrid nature of Computer Mediated Communication (CMC) is clearly suggested by the different appellations given to the language. Soffer notes that terms like 'netlish,' 'netspeak,' 'weblish,' 'Internet language,' and 'cyberspeak' attest to the perception of the hybrid nature of digital discourse, which is composed simultaneously with elements of writing and speech. It is somehow in line with this observation that Crystal David (2008) concedes that less than $10 \%$ of words used in a typical SMS message is abbreviated. This indicates that, according to Crystal, $10 \%$ of the messages are generally presented in unconventional language meanwhile the other $90 \%$ are theoretically composed of literacy features. Crystal further notes that texting is most often done by texters 
who have a foreknowledge of the conventional spelling of the words being used in their texts. In the same line of argument, Dansieh (2013:225) pointedly remarks that, as a language art, text messaging is not just writing anything. Most often, texters do a thorough and intelligent editing before sending out their texts. This editing aims at shaping the message to fit the limited but précised number of words. This makes conditions favourable for the use of graphones and single pronounceable letters - "pronounceable spellings" as Barasa and Mous (2013) call them.

In Nigeria, SMS texting is influenced by some socio-cultural and linguistic factors. Texters are, for instance, often influenced by local (vernacular and vehicular) languages (Feuba 2009). Some of these languages (for instance Igbo and Nigerian pidgin) are principally oral or do not enjoy a conventional (generally accepted) orthography (National Open University of Nigeria 2008; Salawu 2006; Esizimetor 2010; Activie 2010). This theoretically predisposes some of the SMS messages generated by Nigerian texters (who are users of such indigenous languages) to have qualities of oral language and features of the local indigenous language and cultures. This paper aims at determining the extent to which SMS messaging in Nigeria departs from conventional written language (English). It equally investigates into the influence of local languages and cultures on SMS language and attempts to see whether this language (textese) is influenced in its orthography by some vernacular and vehicular languages spoken in Nigeria.

\section{SMS texting and the standard written language}

As earlier mentioned, SMS texting is credited with creating a new language which, to sceptical linguists such as Sutherland (2008) and Thrulow (2007) is "thin, unimaginative, bleak, bald, and shorthand and drab shrinktall". Sutherland (2008) further views textese as a linguistic phenomenon which is "all pig's ear and best described as penmanship for illiterates". Indeed, SMS language totally or partially departs from orthographic and syntactic norms of the language and places particular emphasis on written sounds, abbreviations and compressions (Bouillon and Busa 2013; Pablo 2010; Israel 2012; Dansieh 2013; Richardson and Lenarcic 2009; Feuba 2009, Donovan 2002). Quoting Crystal, Zahid and Mehmood (2013:390) insightfully note the dominant tendency among texters to give little or no attention to the norms of standard language.

Texters are prone to ignore spellings either intentionally or reflexively. The accepted credence is that texting has developed as a twenty-first century trend and a highly idiosyncratic vivid style, full of 
contradictions and out of the ordinary uses of language, used by an immature generation that doesn't worry about standards.

The cumbersome text input and the informal context of SMS communication motivate texters to often sacrifice form for content. Space constraint makes their messages to be miniscule missives, malformed in nature but loaded "with cohesive meaning that at times may appear to border on lyrical composition" (Richardson and Lenarcic 2009:843). In line with this, Feuba (2009:25) argues that the syntactic structure of the SMS text is for the most part "highly disjoined and incoherent". Such incoherence renders the decoding of the message very complex. The decoder is often compelled to strongly rely on pragmatics and shared knowledge to be able to interpret the message (Essoh et al 2014; McGilvray 2013; Carter 2004; Chomsky 2009; Awoyemi 2013:38; Feuba 2009:25).

However, SMS messages are not always constructed exclusively with malformed sentences, abbreviations, onomatopoeic words and other non-conventional formulations. Being a communication instrument mostly for the literate class (Oluga and Babalola 2013; Dansieh 2013; Russel 2010; Volsoo 2009), it is not uncommon to observe linguistic purism in some SMS. Crystal (2008) somehow corroborates this fact when he argues that a typical SMS message has over $10 \%$ of its content constructed with abbreviations. This means that, according to him, the greatest part of the SMS message is remarkably composed of conventional and relatively purist expressions. In the same line of argument, Volsoo (2009) concedes that the art/act of producing and reading SMS texts (messages in digital language) requires, the texters to have the capacity to encode/decode a blend of conventional and non-conventional linguistic formulations. He observes that "While spelled incorrectly in a conventional sense, many textisms are phonologically acceptable forms of written English". He further cites Leakes who insightfully contends that "people [texters] have always used abbreviations [...] They do not actually use that [unconventional spellings] many in texts". It is therefore safe to argue that SMS texts are sometimes composed in both nonstandard and standard language.

In particular SMS communication situations, the formulation of complex ideas is rebellious to any abbreviation effort. Very sensitive communication situations - in which the communicator wishes to reach its communicational target - often warrants a straight forward encoding style which, sometimes, is very much favourable to linguistic purism. This means that abbreviation may sometimes hinder effective communication of ideas, meanwhile conventional formulation would do the reverse. Wood (1991) makes allusion to such a scenario when she notes the two following points as representing characteristics of webslang: 
i) In each case, the reduced system satisfies a correspondingly reduced range of communication needs. These are mainly functional needs, since the system lacks the fine distinction that would transmit subtle concepts and subtle meanings.

ii) As the speaker's needs become more complex or subtle, the system becomes elaborate [accommodating purist formulations of expressions].

Indeed, the SMS technology is conceived for a special (short) type of communication which encourages simplicity and brevity. However, when communication needs become more complex or subtle there is the need to develop a more strategic technique to achieve conciseness. To avoid vagueness or ambiguity, the texters sometimes have to resort to conventional vocabularies (Vosloo 2009; Soffer 2012, Russel 2010, Donovan 2002). This has caused a good number of linguists to categorise SMS messages as being a hybrid kind of discourse, since, as a type of discourse, it possesses qualities of spoken and written language (Soffer 2012; Camilla 2006; Feuba 2009, Crystal 2008). It integrates features of both conventional and unconventional language. Based on this premise, Androutsopoulos (2013:5) views SMS technology and the internet as "a complex meeting of media [that displays both] collaboration and antagonism of orality and literacy, as it is characteristic for phases of media shifts". In the same line of thought, Soffer notes that the textese which is currently performed by wide circles of users, is characterised by deliberate misspelling and exhibits a strong influence of orality on the written text. Soffer thus refers to SMS language as an "Oralwritten text" which ostensibly reflects a melting of linguistic structures and which resembles the changes that occurred in social structures in the late modern era.

\section{SMS texting and the oral language}

According to the structuralist school of thought, written language somehow implies -or is linked to - orality. Drawing on this premise, Sigmund Freud (1962) views writing as being "the voice of an absent person". In the same line of argument, Akporobaro (2012:1) contends that today's written word "is only an outcome of the 'Oral Forms' which are man's earliest and original medium of self-expression and artistic creativity". Indeed, language is so overwhelmingly oral that of all the many thousands of languages - possibly tens of thousands - spoken in the course of human history only about 106 have ever been committed to writing to an extent sufficient to have produced literature. Meanwhile, numerous other languages have never been written at all. Ong (2005:7) notes that out of some 3000 spoken 
languages that continue to exist in today's world, only about 78 have a literature. It is virtually still impossible to determine the number of languages that have disappeared or have been transmuted into other languages before writing came along. "Even now hundreds of languages in active use are never written at all: no one has worked out an effective way to write them. The basic orality of language is permanent" (Ong, 2005:7).

The relation between orality and written language varies with respect to cultures and epochs. As Soffer (2012) rightfully opines, the oral influences on written language are not unique to today's digital culture.

Texts have always been related to the world of sound. Spoken and written language are supposed to correlate, at least to a certain extent. [...] However, the degree to which orality influences the text has varied across different cultural and historical environments. High levels of oral characteristics exhibited in a text seem to reflect the transformation of the written text into the acoustic sphere.

Androutsopoulos (2013:5) uses the term "conceptual orality" to refer to all aspects reminiscent of casual spoken language in written discourse. He draws inspiration from Ulrich Schmitz's concept of 'secondary literacy' which considers Computer Mediated Communication (CMC) as part of a "general tendency for writing to become a transcription of speech". In the SMS language, the oral (orality) plays a great role in the formulation of linguistic expressions bearing the ideas of the texter (Ong 2005; Soffer 2012). Dansieh (2013:224) captures this point in his observation that text messaging mostly involves the use of such phenomena as pictograms and logograms. Words and sentences are either shortened through the use of successive combinations of symbols to represent words, phrases or sentences or by using such symbols whose names sound like words or sentences. A number of linguistic creativity features in SMS messages are therefore based on pronounceable spelling that is, on crafting words or sentences the way they would be pronounced. The oral features of the SMS text include such phenomena as abbreviations, elisions of punctuation, replacement of letters with numbers that have a similar sound, imitation of sounds, among others (Crystal 2008; Soffer 2012; Androutsopoulos 2013).

Barasa and Mouss (2013:237) refer to such an oral-based form of writing as graphones. The graphone as a concept, is derived from the words "graphic" (written representation) and "phone" (speech sound). It refers to a "feature of SMS language in which words are written the way they are pronounced (spoken like 
written)" (Barasa and Mouss 2013). Graphones in SMS discourse - as the other creativity features - are most often influenced by linguistic and socio-linguistic factors. In Nigeria, they are influenced by local languages and some other socioreligious factors (Camila 2004; Barasa and Mouss 2013). In an article titled "The Sociolinguistics of Mobile Phone SMS Usage in Cameroon and Nigeria", Feuba (2009:39-40) notes that:

Cameroonian and Nigerian SMS texters are influenced by their local languages, customs and belief system capable enough to give it a flavour and characteristics that could be distinctly identified as Cameroonian or Nigeria [...] The linguistic and cultural backgrounds of SMS texters stand as a pointer to the feature they are likely to incorporate into their messages hence a thorough study of SMs language should go beyond the general features of SMS linguistic specificities to cultural specificities.

This paper attempts to explore these linguistic and cultural specificities through showing how graphones and other orality features represent a major component of the SMS discourse in Nigeria and how these orality phenomena are influenced by local (vernacular and vehicular) languages such as Igbo, Hausa, Yoruba among others and Nigerian Pidgin English (NPE).

\section{Data and method}

Quantitative and qualitative data was collected through observation and content analysis of sampled SMS texts. A corpus of 2000 texts messages was randomly collected from 500 texters in 5 different towns of Nigeria namely Calabar, Uyo, Lagos, Enugu and Oweri. 1100 of the texts were generated by literate texters (including university students and lecturers, individuals from tertiary education establishments and professional bodies) and the other 900 texts were collected from semi-educated texters (people of secondary education level). The texters, were all drawn from various tribal backgrounds notably Efik, Igbo, Ijaw, Ijagan, Ibiobio, Yoruba, Obudu, Tiv, Hausa among others. They were all English indigenous language bilingual or multilingual. The SMS collected were composed for various purposes and done under varied circumstances such as simple networking, informing students or teachers about classes; extracurricular activities, relevant domestic and academic chores, or socialising purposes among others.

The 2000 SMS messages were analysed by the researchers on the basis of language features and some sociolinguistic variables. The principal aim of the study was to 
explore orality features against literacy elements in the SMS texts gathered. As earlier indicated, the researcher considered orality features to be phenomena such as abbreviations, elisions of punctuation, replacement of letters with numbers that have a similar sound, imitation of sounds, among others (Crystal 2008; Soffer 2012; Androutsopoulos 2013; International Telecommunication Union 2009; D'Agistino 1984). The researcher equally considered literacy features to be parts of the texts that were spelt in correct English. In analysing the data collected, the researchers tried as much as possible to be faithful to the original SMS messages. Accordingly, the translations of the SMS messages into correct English kept the entire syntactic structures of the original SMS. Such translations maintained the spelling, capitalization, punctuation as used in the original SMS.

\section{Discussion of Findings}

The study probes into the various linguistic features observed in the SMS texts messages from both literate and semi-literate texters in Nigeria. It attempts to evaluate the extent to which features of orality may be found in the Nigerian SMS discourse. This section of the study shows to what extent the Nigerian SMS discourse is hybrid - the degree to which it combines both features of orality and literacy. It equally shows how some socio-linguistic factors such as the orthography of some indigenous (Nigerian) languages and the Nigerian Pidgin English do contribute to this hybridity of the Nigerian SMS discourse.

\section{Hybridity of SMS discourse in Nigeria}

Results of the study indicate that the Nigerian SMS discourse has more literacy features than it has characteristics of oral language. Judging from the results of our analysis, literacy features constitute over $54.36 \%$ of the content of SMS messages considered for the study; against $45.05 \%$ for orality features as shown in table 1 below. Results equally point to the fact that these literacy features are dominantly observable in SMS messages formulated by educated texters. On the other hand, orality features are dominant in SMS texts generated by semi-educated texters-

Table 1: Orality Versus Literacy in SMS Messages

\begin{tabular}{|c|c|c|c|c|c|c|c|c|}
\hline & \multicolumn{2}{|c|}{ Literacy } & \multicolumn{2}{|c|}{ Orality } & \multicolumn{2}{|c|}{$\begin{array}{c}\text { Nigerian } \\
\text { Languages }\end{array}$} & \multicolumn{2}{|c|}{ Total } \\
\hline & $\mathrm{n}$ & $\%$ & $\mathrm{n}$ & $\%$ & $\mathrm{n}$ & $\%$ & $\mathrm{n}$ & $\%$ \\
\hline Literate Texters & 16212 & 58.84 & 11321 & 41.09 & 018 & 0.07 & 27551 & 100 \\
\hline Semi-Educated & 3096 & 38.88 & 4680 & 58.77 & 186 & 2.35 & 7962 & 100 \\
\hline Total & 19308 & 54.36 & 16001 & 45.05 & 204 & 0.59 & 35513 & 100 \\
\hline
\end{tabular}


The findings somehow negate Crystal's (2008) claim that only 10\% of text in SMS context is formulated with abbreviations. In the case of the Nigerian SMS discourse, messages are more than $40 \%$ composed with abbreviations and with other linguistic creativity techniques. Though the use of conventional spelling of word varies depending on the level of education of texters, a considerable portion of the texts by the literate undergoes the same linguistic adjustments as in texts generated by semi-educated texters.

As shown in table 1 above, the use of indigenous (Nigerian) languages is equally notable in the construction of SMS messages in Nigeria as over $0.59 \%$ of the text messages is constructed with these features. The trend is more accentuated among the semi-educated texters than among the educated ones. $0.07 \%$ of the SMS texts from educated texters were in pidgin-English and other Nigerian languages while $2.35 \%$ such texts were from semi- educated texters. The use of pidgin-English is the most notable, in this category of texts.

\section{Orality features in Nigerian SMS discourse}

There are various orality features in SMS discourse in Nigeria. These features include word truncation, initialisation, graphones, vewel omission, onomatopoeic words among others, as shown in table 2 below. The table shows that graphones, followed by truncation and vowel deletion represent the dominant orality features in the SMS texts of both literate and semi-literate texters. The less dominant features include initialisation and onomatopoeic formulations among others.

Table 2: Orality Features in the Nigerian SMS Discourse

\begin{tabular}{lcccccc}
\hline & \multicolumn{2}{c}{ Literate Texters } & \multicolumn{2}{c}{ Semi-Literate } & \multicolumn{2}{c}{ Total } \\
\cline { 2 - 7 } & $\mathrm{n}$ & $\%$ & $\mathrm{n}$ & $\%$ & $\mathrm{n}$ & $\%$ \\
Truncation & 2101 & 18.55 & 1063 & 22.71 & 3164 & 19.77 \\
Initialisation & 935 & 8.25 & 307 & 6.55 & 1242 & 7.76 \\
Graphones & 5311 & 46.91 & 1879 & 40.14 & 7190 & 44.93 \\
Vowel Omission & 2198 & 19.41 & 957 & 20.44 & 3155 & 19.71 \\
Onomatopoeic words & 701 & 6.19 & 413 & 8.82 & 1114 & 6.96 \\
Others & 75 & 0.69 & 61 & 1.34 & 136 & 0.87 \\
Total & 11321 & 100 & 4680 & 100 & 16001 & 100 \\
\hline
\end{tabular}

\section{a. Graphones}

Graphones are features of SMS language in which words are spelt the way they are pronounced. Our corpus reveals the use of graphones in SMS messages where words or expressions were spelt the way they would be pronounced rather that 
according to their original spellings. Graphones normally compel the receiver to pronounce the written words aloud (in text), in order to identify and decode the intended word. In our corpus, we observed basically three (3) types of graphones including letter homophones, logographic emoticons and alphanumeric homophones.

Letter homophones are letters that represent whole or parts of words/expressions, due to similarity in pronunciation. From our analysis of the data, it was realised that both literate and semi-literate texters use this feature at almost the same rate (46.91\% of texts generated by the literate contained this feature against $40.14 \%$ in texts by semi-literate texters). Examples of letter homophones include the following:

i) $\mathbf{C} \mathbf{u} 2$ morow and plz $\mathbf{b}$ there = see you tomorrow and please be there.

ii) Wil b done $\mathbf{d} 23$ dis month $=$ I will be done on the $23^{\text {th }}$ of this month.

iii) Pls I'm sorry, I wasn't wif my fone = Please I am sorry, I wasn't with my phone.

iv) Y didn't u send $\mathbf{d}$ mony = Why didn't you send the money.

v) Giv me ur numba = give me your number

vi) Cum I am in ma hauz. = come, I am in my house

As shown in the above mentioned examples, a number of letters has been used by both literate and semi-literate texters to represent whole words or expressions, by virtue of similarities in pronunciation. In line with this letter " $\mathrm{C}$ " has often been used for "see", while "U" has been used for "you", and "B" for "be", "Y" for "why" among others. In other instances, letters were used to stand for parts of a number of words or expressions. This is seen in the case of "dis" which often stood for "this" and "numba" stood for "number". To this list of letter homophones, we may add those that were very much influenced by local language such as Pidgin English. The example given at (v) and (vi) above aptly illustrate this category of letter homophones. In these examples, the words "numba", "ma" and "hauz" respectively standing for "number", "my" and "house" show some influences of the Nigerian Pidgin English. In Pidgin English language, the English sounds [ $\alpha$ :] and $[æ]$ are often wrongly used for [ə] and [aI]. The nasalisation of the [s] sound in "house" in the spelling of the word "hauz" also illustrates some phonological interference from texters' indigenous languages. It has amply been demonstrated by a number of Nigerian linguists that speakers from the Hausa, Ijaw, Ibibio (of Nigeria) and the like often pronounced [s], [dz], [ð], sounds among others as [z] (Ugot 2010: 7-9; Balogun 2013: 96, National Open University of Nigeria 2008). 
Logographic emoticons represent another type of graphones encountered in the SMS texts by Nigerians. These features have to do with the use of icons to denote emotions. Logographic emoticons facilitate the construction of meaning through the object and events acting as "sign" in relation to other signs (Feuba 2009). Examples of such signs drawn from our corpus include the use of "@" to mean "at", "\$" or "\&" to mean "and", "+" to mean "and"; "(:)" and "+t" respectively to indicate a smile and unhappiness. The use of these signs can be illustrated with the following examples:

vii) Service is @ R.C., Jesus Palace Awi. = service is at Redeem Church, Jesus Palace Awi.

viii) $\mathrm{U}$ came into my lyf $\boldsymbol{\&}$ made me feel so special. $=$ You came into my life and made me feel so special

ix) D nt forget 2 bring $d$ money $\$$ my cloths. = do not forget to bring the money and my cloths.

x) Don't be sad. Smile for me, like this :).

xi) He insulted me, - the fact that him $+\mathrm{d}$ wife did not pay my mony. $=$ He insulted me, beside the fact that his wife and him failed to pay my money.

Alphanimeric homophones constitute the third type of graphones employed by Nigerian texters. Alphanumeric homophones are formulations that combine letters and numbers to represent words or clauses. Examples from our corpus indicate that numbers and signs are used for complete words or integral parts of words or clauses. Consider the following examples:

xii) Will cum 2day b/4 8PM. If nt, w8t 2morow. = I will come today before 8 P.M. If not you might wait till tomorrow.

xiii) U r 2truly de Lord's chosen. = You are truly the Lord's Chosen.

xiv) Till d8, he has not $\mathbf{p 8}$ my mony. Still w8ting. = Up till today, he has not paid my money. I am still waiting.

\section{b. $\quad$ Vowel deletion}

Vowel deletion/omission occurs when sets of vowels in a word are deliberately omitted while consonant are kept, in order to achieve brevity through contraction of words. The results of the study indicate that this feature was used more by semiliterate texters than by those of the literate category $(20.44 \%$ of texts from the semi-literate as against $19.41 \%$ from the literate). Examples for our corpus indicate the contraction of such words as "your" or "year" as "yr", "from" as "frm", "not" 
as "nt", "please" as "plz"/ "pls"; "place" as "plc" and the like. Vowel deletion is further illustrated in the following examples:

xv) Swthrt hapi bday, nd hav a gr8 celebration. = sweetheart, happy birthday, and have a great celebration.

xvi) Hop u $\mathbf{r}$ cumin $\mathbf{n} \mathbf{w}$. = Hope you ar coming now.

xvii) Pls hu am I chrtin wif. = please, who am I chatting with?

xviii) Hav u nt sn ma pix. = Have you not seen my picture ?

xix) I av ltd tym in Klas dis evening.= I have limited time dis evening.

xx) Hlo I'm @ ma plc. R u cuming?=Helo, I am at my place. Are you coming?

\section{c. Truncation}

Truncations are orthographic transformations whereby, words are clipped for the sake of brevity. The data show that the semi-literate equally used this feature more than the literate. Given the fact that truncations are most often personalised forms of formulations, they may be very difficult to decode by the ordinary language user. The following examples illustrate this orality feature:

xxi) Hw ar u doing api Sunday. = How are you doing? Happy Sunday.

xxii) No shadows 2 depress $u$, only apiness 2 surround $u$. = no shadows to depress you, only happiness to surround you.

xxiii) Hop u slept well. = Hope $\mathrm{u}$ had a goodnight.

xxiv) Am riting Xam now . = I am now writing exam.

$\mathrm{xxv}$ ) $\mathbf{T} \mathbf{x}$ for ur assist. = thanks for your assistance

\section{d. Initialisation}

Initialisation as a creativity and orality feature involves the use of letters to represent whole words, expressions or sentences. They are basically used to shorten the text message. Results from the study indicate that it is among the less dominant techniques used in SMS formulations by both literate and semi-literates in Nigeria. Examples to illustrate the use of initialisation include the following:

xxvi) Munny gud AM. This is my dad's No.

xxvii) May God continue to bless every plan of ours IJN: Amen. = may God continue to bless each plan of ours, in Jesus' Name: Amen.

xxviii) Plz I wil need ur BK. Please, I will need your book.

xxix) C, will never b ur GF. Ok. = See, I will never be your girl friend. $\mathrm{Ok}$ ? 
The words presented in bold represents initialisations. Apart from "AM" which "symbolically"/analogically employed to refer the word "morning", the other words are shortened forms that directly refer to particular words. "IJN" is for instance used as a personalised form of linguistic creativity the same as the initials "GF".

\section{e. $\quad$ Onomatopeic expressions}

We equally registered a number of onomatopoeic expressions mainly used for prosodic effects. Examples include such exclamatory expressions such as "ewo", "O boy", "chei", "eya", "hei", "eh", "wow" and the like. Some of these exclamatory expressions were written with duplication or repetition of vowels as in the following examples:

xxx) Nooooooooo!!!! U got it wrong! = No, you got it wrong!

xxxi) Eyaaaaaaa! Sory my dear. = well, I am sorry, my dear.

xxxii)Ewooooo!! U no go kill me. = What! You wouldn't kill me (transliteration).

It can be noticed that most of the exclamatory expressions with deplication and repetition of vowel aim at achieving stress as in actual speech and to represent the oral reality in a written (creative) way. The use of such onomatopoeic expressions represent personalised use of creativity features in SMS communications.

\section{Conclusion}

This paper has attempted to show to what extent orality shapes the content of Nigerian SMS discourse. It probed into the various linguistic features observable in the SMS texts messages from both literate and semi-literate texters in Nigeria and has attempted to evaluate the extent to which features of orality may be found in the Nigerian SMS discourse. It argues that the Nigerian SMS discourse has more literacy features than it has characteristics of oral language. These literacy features are dominantly observable in SMS messages formulated by literate Nigerian texters. On the other hand, orality features are dominant in SMS texts generated by semi-educated texters. The principal orality features observable in these SMS texts include graphones, vowel deletion, initialisation, onomatopoeic expressions, truncation among others. 


\section{References and Notes:}

Akporobaro, F.B.O. (2012). Introduction to African oral Literature, Lagos: Princeton Publishing Co.

Androutsopoulos, J. (2013). Language Change and Digital media: A Review of

Conceptions and Evidence. In Nik Coulland and Tore Kristianse (Eds) Language Standardisation in Europe. Hamburg: Routledge, pp. 1-15.

Ativie, A. C. (2010). "Cultural Influence as Inputs of Development of Naija Language". Proceedings of the Conference on Nigerian Pidgin, University of Ibadan, Nigeria, 89 July 2009.

Awoyemi, T. (2013). Emergent Trends in English Usage: Language and the Internet. International Journal of English Literature and Culture. 1(2), 33-40.

Balogun, T. A. (2013). In Defense of Nigerian Pidgin. Journal of Language and Culture, 4(5), 90-98.

Barasa, S. \& Mous, M. (2013) The Oral and Written Interface in SMS: Tachnologically Mediated Communication in Kenya. The Oral and Written Interface in SMS in Kenya. 16(2), 547-665.

Bodomo, A.B (2009). Computer-Mediated Communication for Linguistics and Literacy: Technology and natural Language Education. Hershey, PA,: IGI Global.

Bouillon P. and Busa, F. (2013) Linguistic Creativity and the Lexicon. In Bouillon and

Busa (Eds) The Language and Word Meaning, (pp. 1-4), Cambridge: Cambridge University Press.

Carter, R. (2004). Language and Creativity. The Art of Common Talk. London: Routledge.

Carter, R. (2007) Response to Special Issues of Applied Linguistics Devoted to language Creativity in Everyday Context. Applied Linguistics, 28(4), 597-608.

Chomsky, N. (2009). Cartesian Linguistics. A Chapter in the History of Rationalist Thought (Third Edition). Cambridge: Cambridge University Press.

Crystal, D. (2008). Txtng: The Gr8 Db8. Oxford: Oxford University Press.

D’Agostino, F. (1984) Chomsky on Creativity. Synthese 58, 85-117.

Dansieh, S. A. (2013). SMS Texting and its Potential Impacts on Students' Written Communication Skills. In International Journal of English Linguistics, 1(2), 222-229.

Donovan, N. (2002). Victoria Pushes for Texting School Subject. The World Today, [Online] Available http://www.abc.net.au/worldtoday/content/2006/s1760068,htm. (May 15, 2015).

Esizimetor, O. D. (2010). "Historical Development of Naija" Proceedings of the Conference on Nigerian Pidgin, University of Ibadan, Nigeria, 8-9 July, 2009.

Essoh et al (2013). Creativity Features in SMS Text by Anglophone Learners and Teachers of the FLE. JOLACE: Journal of language and Cultural education, 2(3), 79-95.

Feuba, W. E. (2009). The Sociolinguistics of Mobile Phone SMS Usage in Cameroon and Nigeria. The International Journal of Language Society and Culture. 28, 25-40. International Telecommunication Union (2009). Information Society Statistical Profiles 2009: Africa. Johannesburg: ITU. 
Isreal, M. (2013) Consistency and Creativity in First language Acquisition. Journal of Linguistic, 25(4), 23-57.

Ling, R. (2005). The Sociolinguistics of SMS: An Analysis of SMS use by a Random Sample of Norwegians. London: Springer.

McGilvray, J. (2013) Chomsky on the Creative Aspect of Language Use and its Implications dor Lexical Semantic Studies. In Bouillon and Busa (Eds) The Language and Word Meaning, (pp. 5-18), Cambridge: Cambridge University Press. National Open University of Nigeria (2008). Spoken English. Lagos: NOUN.

Oluga, O. S. \& Babalola, H. A.L. (2013). An Exploration of the Pros and Cons of the Text Message Communication System. International Journal of Asian Social Science. $3(2), 334-344$.

Ong, W. J. (2005). Orality and Literacy. London: Routledge.

Pablo, G. (2010). Engineering Linguistic Creativity: Bird Flight and Jet Planes. Proceedings of the NAACLHLT 2010. Second Workshop on Computational Approaches to Linguistic Creativity, (pp. 23-40), Los Angeles: Association of Computational Linguistics.

Richardson J. \& Lenarcic, J. (2009). The Blended discourse of SMS Communication in a Mobile Student Administration System in Same Places, Different Spaces. Proceedings Ascilite Auckland. [Online] Available on http://www.ascilite.org.au/conferences/auckland09/procs/richardson.pdf. (May 5, 2014).

Russell, L. (2010). The Effects of Text Messaging on English Grammar. [Online] Available: http://www.ehow.com/list_5828172_effects-text-messaging-englishrammar.html. (May 16, 2014).

Salawu, A. (2006). Paradox of a Milieu: Communicating in African Indigenous Languages in the Age of Globalization in Salawu A (Ed) Indigenous Language Media in Africa. (pp.1-20), Lagos: Center for Black and African Arts and Civilisation.

Soffer, O. (2012). Liquid Language? On the Personalisation of Discourse in the Digital era. New Media and Society, London: Sage. Pp. 1-19.

Sutherland, J. (2008). Can U Txt? Jonh Sutherland asks what Texting is doing to the English Language - and finds it all a bit: The Gardian Newpaper, June 13:6.

Szerencsi, K. (2010) The Need for Linguistic Creativity in Foreign Language Classroom Discourse. Acta Universitatis Sapientiae, Philologica, 2(2), 286-298.

Thurlow, C. (2007). Fabricating Youth: New-Media Discourse and the Technologization of Young People. In S. Johnson and A. Ensslin (Eds) Language in the Medi Representations, Identities, Ideologies (pp. 213-233), London: Continuum.

Ugot, M. (2010). English Language and the Mother Tongue Interference: The Nigeria Perspective. WAACLALS: West African Association for Commonwealth Literature and Language Studies, 3(2), 1-19

Veale, T. and Butnariu, C. (2012) Exploring Linguistic Creativity Via Predictive Lexicology. Dublin:University College Dublin.

Volsoo, S. (2009). Effects of Texting on Literacy: Modern Scourge or Opportunity. Language and the Digital Age, London: Shuttle-work Foundation, pp. 1-8. 
Yousaf, Z. \& Mehmood A. (2013). Effects of SMS on Writing Skills of the University Students in Pakistan (A Case of university of Gujrat). Asian Economic and Financial Review. 3(3), 389-397.

\title{
Summary
}

\section{Orality versus literacy in the Nigerian SMS discourse}

\author{
Endong, Floribert Patrick C. \\ University of Calabar, Nigeria

\section{Essoh, Ndobo Eugenie Grace \\ University of Calabar,Nigeria}

The SMS discourse is generally known to be hybrid in nature, as it very often combines features of both orality and literacy. In line with this, numerous labels - such as oral-written text, netlish, netspeak and the like - have been employed in reference to the phenomenon. These appellations point to the hybrid nature of the phenomenon. This article attempts to show to what extent orality shapes the content of Nigerian SMS discourse. It probes into the various linguistic features observable in 2000 SMS texts messages generated by both literate and semi-literate texters from 5 Nigerian towns (including Lagos, Enugu, Calabar, Uyo and Oweri), in view of evaluating the extent to which features of orality may be found in the Nigerian SMS discourse. It argues that the Nigerian SMS discourse has more literacy features than it has characteristics of oral language. These literacy features are dominantly observable in SMS messages composed by literate Nigerian texters. On the other hand, orality features are dominantly present in SMS texts generated by semi-educated texters. The principal orality features observable in these SMS texts (from both literate and semiliterate texters) include graphones, vowel deletion, initialisation, onomatopoeic expressions, truncation among others.

Keywords: Computer Mediated Communication, Orality, Literacy, SMS Discourse, Linguistic Creativity, Nigerian Languages. 